\title{
Locational Investment Signals: How to Steer the Siting of New Generation Capacity in Power Systems?
}

\author{
Anselm Eicke, ${ }^{a *}$ Tarun Khanna, ${ }^{a, b}$ and Lion Hirth ${ }^{a, b, c}$
}

\begin{abstract}
New generators located far from consumption centers require transmission infrastructure and increase network losses. The primary objective of this paper is to study signals that affect the location of generation investment. Such signals result from the electricity market itself and from additional regulatory instruments. We cluster them into five groups: locational electricity markets, deep grid connection charges, grid usage charges, capacity mechanisms, and renewable energy support schemes. We review the use of instruments in twelve major power systems and discuss relevant properties, including a quantitative estimate of their strength. We find that most systems use multiple instruments in parallel, and none of the identified instruments prevails. The signals vary between locations by up to 20 EUR per MWh. Such a difference is significant when compared to the levelized costs of combined cycle plants of 64-72 EUR per MWh in Europe.
\end{abstract}

Keywords: Electricity markets, Locational signal, Generation investment, Market regulation, Incentive regulation

https://doi.org/10.5547/01956574.41.6.aeic

\section{INTRODUCTION}

The construction of network infrastructure is costly, subject to lengthy permitting processes, and often met by public resistance. However, the integration of newly constructed power generation facilities results in a significant rise in transmission infrastructure needs in many parts of the world. There are three major reasons for this increase. A first is the expansion of wind and solar energy. These energy sources are produced at least cost where land is cheap and resource availability is high, which is often far away from energy consumption centers. ${ }^{1}$ Second, the legacy of regional energy monopolies is fading 20 to 30 years after restructuring the electric power industry in many parts of the United States and Europe. Historically, these utilities were the primary investors in local generation capacity. Last, European power markets are increasingly closely integrated, which has resulted in a rising long-distance trade of power, and by association, in load flows.

As a consequence of the increasing distance between load and generation, strain on transmission infrastructure is increasing and generators in many regions have experienced significant

1. One out of many examples is the German power system: most renewable energy generators are being built in the north and the east of the country whereas major load centres are in the south.

\footnotetext{
${ }^{a}$ Hertie School, Berlin.

${ }^{\mathrm{b}}$ Mercator Research Institute on Global Commons and Climate Change (MCC).

${ }^{c}$ Neon Neue Energieökonomik GmbH.

*Corresponding author. E-mail: eicke@hertie-school.org, Hertie School, Friedrichstraße 180, 10117 Berlin.
} 
curtailment over the last years (Bird et al., 2016). One way to reduce the pressure on the infrastructure is to site generation assets and end users closer to each other. Such locational steering can be applied to generators and to consumers. The primary purpose of this paper is to providing a comparative review of locational investment signals applicable to generators. Politically, it is much easier to introduce cost (or revenue) differences for generation compared to discriminating against consumers.

In Europe, zonal electricity markets prevail. A textbook zonal electricity market does not provide any locational incentive within a zone, which implies that the choice of where to invest is purely driven by the costs of power generation. In the case of wind and solar energy, these are cost of land and resource quality. Cost differences between coal-fired power plants mostly stem from coal transportation costs.

However, the social cost of power supply not only comprises generation costs but also includes the costs of the accompanying network. ${ }^{2}$ The latter includes infrastructure costs and costs associated with congestion and transmission losses. Socializing these costs implies they are not accounted for in investment decisions. This is a classical externality problem (Alayo, Rider, and Contreras, 2017). It leads to a cost-inefficient distribution of generation investment, with generation capacity being installed too far from consumers and grid investments being too large.

The socially optimal location of power generation, in terms of (social) cost-efficiency, depends on the difference in generation costs between locations and on network costs. If generation costs were unrelated to network costs, the (trivial) cost-optimal location of generation would be at sites where generation costs are lowest. Yet, the cost of power generation is in practice often low at sites which strain the network, e.g. wind generation at windy but remote sites. In these cases, social costs are minimized when the marginal cost of relocating generation equals the marginal cost saving in the transmission system (Figure 1). In other words, it is cost-efficient to relocate generators if the resulting savings in network costs exceed the additional costs of generation at the new site. Well-designed locational signals therefore compel generators to consider transmission- and congestion-related costs in their siting decision.

Figure 1: At the social optimum the combined cost of generation and transmission are minimized (schematic representation, no relocation of demand)

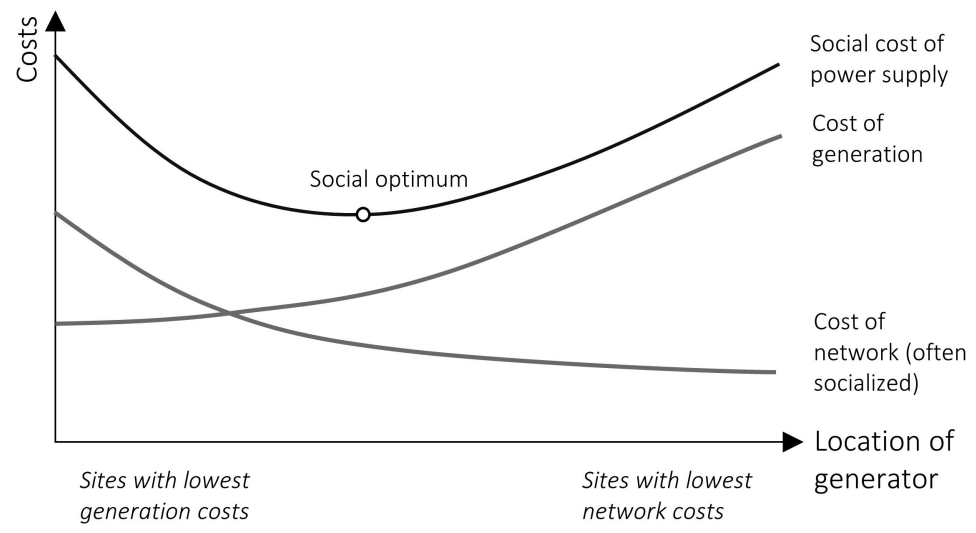

2. Other costs can also be considered part of the social cost of power supply, e.g. balancing cost. For our analysis on locational signals, we focus on the two mentioned components. 
Unlike textbook zonal markets, most real-world power systems provide locational signals to generators. Such signals often stem from regulations outside the market, including grid connection charges, grid usage charges, capacity mechanisms, and renewable energy support schemes. Some power markets have also introduced spatial granularity into the market itself in the form of smaller zones or locational pricing. We use locational instruments as an umbrella term for this variety of regulation. The aim of this paper is to discuss locational instruments from a theoretical perspective and review their use empirically.

A vast amount of published literature covers many of these instruments - Google Scholar reports 4,100 papers related to "locational marginal pricing" alone. However, this body of research often does not consider the instruments as locational investment incentives. Locational pricing, for example, is generally viewed as a dispatch incentive (Joskow, 2008), and grid charges are widely considered to be a cost recovery mechanism (Olmos and Pérez-Arriaga, 2009).

Only a few authors compare locational investment incentives across instruments. Hadush et al. (2011) examine market splitting, loss factors, grid usage charges and grid connection charges associated with European case studies. The authors assess each instrument's effect on investment decisions based on the criteria stability, predictability and strength. Brunekreeft et al. (2005) propose that additional locational instruments complement locational marginal pricing to signal the cost-efficient location of generation investments. The authors base their argument on the observation that locational marginal prices do not recover all grid costs, and therefore do not fully internalize the actual locational value differences of generation. They discuss grid usage charges and deep grid connection charges as supplementary locational instruments. Keller and Wild (2004) assess how coordination between transmission and generation investment can take place in liberalized power markets. To do so, the authors examine locational investment signals arising from transmission pricing. Nikogosian et al. (2019) analyze grid connection charges, regional quotas, and regional premiums with respect to steering the siting of renewable energy assets in Germany. Their study concludes that among these three, regional quotas are the most effective and easiest to implement in the context of the German energy market. Locational investment signals are considered as a means of reducing grid congestion by Hirth et al. (2018). In their categorization, the authors cluster instruments in a manner similar to that which was employed in this study. To the best of our knowledge, a review of the different classes of instruments has not been conducted so far.

The objective of this paper is to close that gap in the literature by providing a comparative review of locational investment signals applicable to generators. More specifically, our contribution to the literature is three-fold. First, we propose ten dimensions to characterize locational instruments. Secondly, we review the locational instruments used in twelve power systems and finally, we introduce a simple methodology to quantify the strength of these instruments and employ it.

We find that every power system employs at least one instrument, and most systems use multiple locational instruments in parallel. In practice, most of the analyzed locational electricity markets apply regulation on top of a granular market to steer the location of investments. We further observe that instruments differ significantly in design, and there does not appear to be a "silver bullet" instrument, which represents the best option for all systems. The effect of many of the locational instruments on investment decisions is reduced due to lack of predictability, low levels of transparency, and insufficient spatial and temporal accuracy.

The remainder of this paper is structured along our three contributions: section 2 presents our analytical framework, section 3 identifies which instruments are used where, and section 4 quantifies their impact. 


\section{TEN RELEVANT CHARACTERISTICS OF INSTRUMENTS}

The effect of locational instruments on investment decision-making depends on their design. This section proposes ten distinct design characteristics that influence efficacy and nature of the locational signals that such instruments provide. In the following section, we apply these characteristics to structure the review of locational instruments in our sample and discuss their implications.

1. Price or quantity. Locational instruments can be designed as price or quantity instrument. For price-based instruments, the difference in the cost or revenue between locations is determined by the regulator, for example grid usage charges that are differentiated by location. By contrast, quantity instruments are characterized by upper or lower capacity thresholds in a region. Regional quantity limits for renewable energy deployment are an example of this. In an efficient market, such a quantity constraint translates into a "virtual" price signal (Neary and Roberts, 1980). Price-based instruments benefit investors by making it easier to ascertain value differences between locations. Integration costs that result from connections at certain locations can be transferred directly to project developers. By contrast, quantity-based instruments are valuable because they provide a simple and effective way to steer generation investment and account for quantity constraints (e.g., limited transmission capacity is easy to account for). Most instruments identified in this study are pricebased.

2. Per energy or per capacity. Locational signals remunerate or charge generators based on the total amount of energy produced (MWh) or the generation capacity installed (MW). Depending on the design of these instruments, technologies are affected differently. Capacity-based signals have a stronger impact on technologies with a low capacity factor, such as peaking plants or renewable energy sources, while energy-based instruments have a more significant effect on generators with high capacity factors such as base load plants. To support this point, compare two hypothetical generators. Peak generator P with a capacity of $2 \mathrm{MW}$ is operated 1000 hours per year, and base load generator B has $1 \mathrm{MW}$ of capacity and is operated for 8000 running hours. An instrument that creates a wedge of $10 € / \mathrm{kW}$ between two locations (i.e., a capacity-based instrument) will impact P's net present value twice as much as B's. By contrast, an instrument that creates a wedge of $1 € / \mathrm{MWh}$ between two locations (i.e., a production-based instrument) will affect B four times stronger than $\mathrm{P}^{3}$

3. Temporal granularity. The value difference of generation between two locations varies over time. Time-invariant instruments fail to reflect this. We explain this by way of the example of two interconnected regions: a surplus region $\mathrm{S}$ and a deficit region $\mathrm{D}$. In $\mathrm{S}$, generation exceeds demand most of the time; the opposite is the case for D. In a long-term equilibrium and without lumpiness in grid investments, the marginal value difference between two locations equals the marginal network costs of transmitting electricity between them. In hours when power flows from $\mathrm{S}$ to $\mathrm{D}$, generation in $\mathrm{D}$ has a higher value than in $\mathrm{S}$ because it reduces the use of the network and thereby reduces marginal network costs. This value difference rises with increasing costs of congestion management and transmission losses. When no grid constraints occur, it is close to zero and a negative value difference implies a power flow from $\mathrm{D}$ to $\mathrm{S}$. Neither constant energy-based instruments nor capacity-based instruments reflect this temporal variability (Figure 1). When grid congestion is present in the predicted direction (i.e., from $\mathrm{S}$ to $\mathrm{D}$ ), the locational signal is often too weak. In hours without grid congestion, the signal unnecessarily incentivizes generation in $\mathrm{D}$ and even aggravates grid congestion when S temporarily lacks supply.

3. In the first case, the impact of the instrument on the NPV of P is $20,000 €$ whereas its impact on B is $10,000 €$. In the second case, the impact on P is just $2000 €$ annually while the impact on B is $8000 €$. 


\section{Figure 2: Time-invariant locational signals cannot reflect the marginal value difference} between two locations, which varies over time.

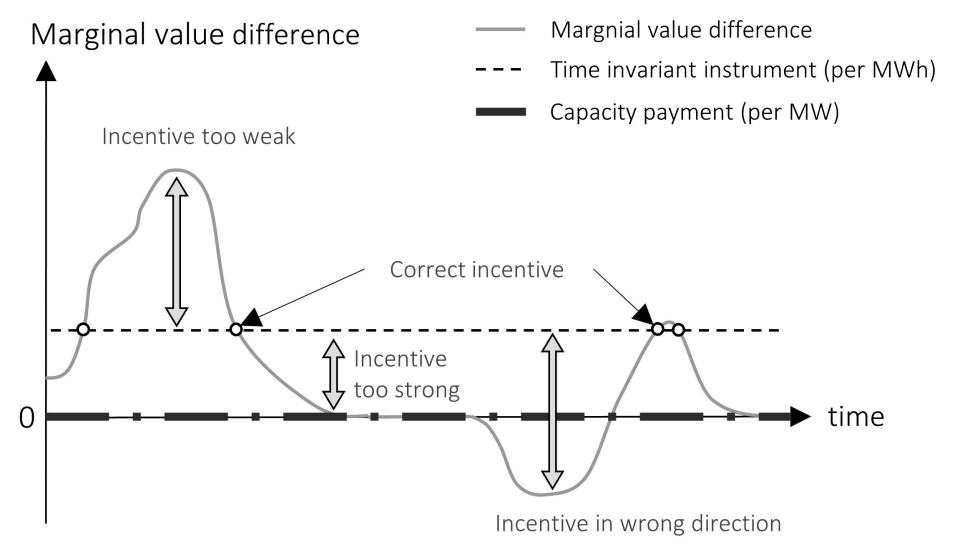

4. Spatial granularity. How well signals reflect grid constraints depends on multiple properties including their spatial resolution. Some instruments have a nodal resolution, whereas others result in uniform signals within a (sub-)region. Depending on the grid topology, a zonal resolution may be insufficient to reflect bottlenecks in the grid. On the other hand, a zonal design is less complex, which improves transparency. High spatial granularity is also prone to the abuse of market power when prices are not set administratively because only one or just a few suppliers are connected at each location (Bigerna, Bollino, and Polinori, 2016).

5. Predictability of signals. For an investment decision, the expected price signal foreseen by the investor matters, and not as it eventually materializes. Hence, the better investors can predict the signal, and the more they trust that the signal will not change over the lifetime of their generation assets, the stronger the instrument's impact on investment decisions. Price signals tend to be more predicable if they occur only once with the investment (e.g., grid connection charges, support schemes), or if they are kept stable over long periods of time (e.g. a grid usage fees adjusted once every 10 years).

6. Transparency of signals. A transparent and rule-based determination of signals improves predictability. Methods and assumptions employed to determine locational signals are available to the public in some but not all cases. One way to provide information on future locational value differences is the dissemination of grid investment plans.

7. Ex-ante or ex-post calculations. Locational signals arising from regulation can be differentiated between signals that are determined and announced ex-ante and those that are determined ex-post, e.g. based on the historical use of grid infrastructure. A major distinction is that ex-post signals are uncertain and can only be forecasted imperfectly, whereas ex-ante signals are known before investment. Certainty about future signals may have greater impact on investment decisions, because market participants can better account for them. On the other hand, ex-post signals may have desirable effects on the dispatch of generators if charges can be reduced through certain producer behavior (e.g., by reducing generation at times of network congestion).

8. Premium or penalty. It is the instrument's diverging effect on different locations that affects siting decisions. Such a difference can be introduced through premiums (i.e. payments to generators), penalties (i.e. charges from generators), or a combination of both. Combining premi- 
ums and penalties allows locational instruments to be revenue-neutral; premiums paid to some generators are financed by penalties to others. Such a design does not increase the average cost of power generation. By contrast, unidirectional instruments affect the overall costs of power generation. A penalty-only scheme is often used to recover expenses (e.g. for transmission infrastructure investment and operation) while a premium-only scheme mostly serves promoting certain technologies (e.g. renewable energy sources or peak generators).

9. New or incumbent generation. Some instruments only affect new generators, while others affect all of them. Targeting existing generators is not effective because they cannot change their location. Such an approach may also increase regulatory uncertainty and may therefore deter future investment. On the other hand, a system that discriminates against new generators compared to existing generators may impede investment if designed as penalty-only system.

10. Strength of the signal. Obviously, not the mere existence, but the magnitude or strength of signals is relevant for siting decisions: a stronger locational signal is more likely to affect the location of new generators than a weaker signal. We define the strength of a signal as the value or cost difference (per $\mathrm{kW}$ or per MWh) it induces between locations.

\section{REVIEW OF LOCATIONAL INSTRUMENTS}

This section provides an overview of the locational instruments currently applied in selected countries. We first present our review approach, and then describe instrument by instrument. We show where instruments are used and discuss them by making use of the first nine characteristics of section 2. The tenth characteristic, the strength of locational signals, is quantified and discussed in section 4.

\subsection{Case selection and review approach}

We review the use of locational instruments in twelve power systems. To this end, we study systems in Chile, France, Germany, India, Mexico, Norway, Sweden, and the United Kingdom, CAISO, PJM, and ERCOT in the United States, and the National Electricity Market (NEM) in eastern and southern Australia. We selected these power systems because they employ liberalized power markets and provide sufficient data transparency. ${ }^{4}$ We also aimed for geographic and market design diversity (i.e., zonal and locational marginal pricing).

In total, we were able to identify 28 locational instruments. To provide an overview and compare features, we clustered all locational instruments into the following five groups based on their economic workings: ${ }^{5}$

- locational electricity markets (i.e., sub-country zones or locational marginal pricing)

- grid connection charges (i.e., one-off costs for connecting to the grid)

- grid usage charges (i.e., ongoing charges for using the grid)

- capacity mechanisms, such as capacity markets, payments, and local tenders

- renewable support schemes such as feed-in-tariffs

All power systems use some form of grid charge, most have support schemes for renewable energy, and many use capacity mechanisms. However, these instruments are uniform across the power sys-

4. India has officially a liberalised power market and, most importantly for our analysis, generators are free to choose the location of their asset.

5. A similar grouping has been proposed in Maurer et al. (2018) and Hirth et al. (2018). 
tem in many cases. For the purposes of this paper, we are interested in these instruments only to the extent that they (a) apply to generators and (b) have locational granularity (i.e. they differ from one site to another). Only when both conditions hold, an instrument provides a signal to steer generation investment geographically. Often, such instruments are primarily designed for other purposes such as cost recovery, wealth distribution, or security of supply. In some instances, the instrument is not intended to provide a locational signal to investors.

The proposed grouping is not unambiguous. Unlike others, we classify market splitting and locational marginal pricing as one instrument due to their structural similarities. In the literature, deep grid connection and grid usage charges are often collectively considered as grid charges (Ignacio J. Pérez-Arriaga and Smeers, 2003). Also the distinction between capacity mechanisms and renewable support schemes is not always clear-cut. For instance, Mexico's clean energy support scheme supports nuclear power plants, some types of gas turbines, and renewable energy sources through capacity and energy payments.

The primary literature reviewed in this study includes national regulation as well as reports published by international organizations and scientific articles as secondary literature. To validate our findings, we conducted 11 interviews with national experts, and discussed results with 15 experts and stakeholders at a workshop held in Berlin in February 2019.

\subsection{Locational electricity markets}

Locational markets provide signals through a spatial granularity of the power market itself and thus differ from all other instruments that work on top of the market. We distinguish between two types of locational electricity markets: locational marginal pricing (also known as nodal pricing) and market splitting. Locational marginal prices account for short-term marginal costs of generation and transmission at each node in the network and are certainly the best known locational instrument. Schweppe et al. (1988) were the first to elaborate that market design. Since then, locational marginal pricing has been introduced in many markets and discussed extensively in the literature (e.g. Green, 2004; Hogan, 1999; Holmberg \& Lazarczyk, 2015; Neuhoff et al., 2013) but often with a focus on dispatch incentives. Another method of introducing spatial granularity in electricity markets is to split power systems into multiple smaller zones. Under this so-called market splitting, price differences reflect limited transmission capacity and network losses between zones. A regulatory risk of reconfigured pricing zones is a main drawback of market splitting (Deilen et al., 2019). Structural uncertainty about the future market design can even have a significant impact on investment decisions, as Ambrosius and al. (2019) show.

Among our sample, nine power systems feature locational electricity markets. CAISO, Chile, ERCOT, Mexico and PJM introduced locational marginal pricing while Australia, India, Norway, and Sweden split their power system into several zones. ${ }^{6}$ The spatial granularity of these instruments differs significantly between countries, which also reflects the geography and density of the population (Table 1).

Locational electricity markets are price-based instruments; local prices per MWh provide signals for dispatch and investment decisions. Because prices are determined in real time, the temporal resolution of locational electricity markets is high. Prices reflect the temporal variability in the value difference between locations and are therefore the sole instruments that provide suitable dispatch incentives. However, the effect of locational electricity markets on investment decisions

6. The classification of a power system is to some extend arbitrary. Often impacted by national borders, the size of power systems varies strongly, see for example the cases of India and Norway. 
Table 1: Spatial resolution of locational electricity markets

\begin{tabular}{|c|c|c|c|}
\hline \multicolumn{2}{|c|}{ Locational marginal pricing } & \multicolumn{2}{|c|}{ Market splitting } \\
\hline PJM & 10300 nodes & India & 13 zones \\
\hline CAISO & 9700 nodes & Australia & 5 zones \\
\hline ERCOT & 8000 nodes & Norway & 5 zones \\
\hline Mexico & 2417 nodes & Sweden & 4 zones \\
\hline
\end{tabular}

is limited due to the high variability and poor predictability of prices (Brunekreeft, Neuhoff, and Newbery, 2005). Even more problematic, significant deviations of current prices from their longterm equilibrium results from the lumpiness of transmission investment. ${ }^{7}$ Green (2003) argues that locational marginal prices may even incentivize wrong locations. Transparency in grid investments is key to increase predictability in future locational value differences and avoid investment in locations where grid extension will take place soon. The spatial granularity is high for locational marginal prices but comparably low for market splitting, depending on the size of zones. Locational electricity markets affect both existing and newly constructed generators.

\subsection{Grid connection charges}

A grid connection charge is a single payment to the network operator for connecting a plant to the grid. In some countries, generators are charged the costs of connecting to the nearest substation ("shallow connection charges"). Elsewhere new generation projects must finance expansion and upgrades in the grid infrastructure that become necessary following the new connection ("deep grid connection charge"). Deep grid connection charges internalize a portion of the grid extension costs (i.e. investors are charged for the grid extension they cause). A locational signal arises because these costs vary by location and depend on the existing grid. The use of deep grid connection charges to internalize costs of the transmission system has been discussed extensively in the literature (Olmos and Pérez-Arriaga, 2009; Swider et al., 2008; Vogel, 2009).

Among the selected power systems, six apply an instrument that we classify as a deep grid connection charge, including CAISO, France, Mexico, PJM, Sweden, and Norway. Table 2 presents the basic characteristics of each approach. Beyond our sample, ENTSO-E provides an overview of deep grid connection charges in Europe (ENTSO-E, 2018).

All deep grid connection charges are levied per unit of installed capacity and therefore affect technologies with lower capacity factors more severely. The geographical resolution of grid connection charges is high if calculated for every grid connection point individually. Its locational signal does not vary over time and consequently does not reflect changes in the value difference between locations. The virtue of this permanence is a predictable signal: as a one-time payment, the locational signal does not vary after the project's commissioning. To benefit most from this characteristic, the charge needs to be known before the final investment decision, which was not the case in all reviewed energy systems. Transparency in the complex and often ambiguous process is an issue for many real-world instruments. We were not able to identify the precise methodology used to determine charges in most cases. Often, costly connection studies must be commissioned from the network operator first to identify suitable locations. Given the many assumptions necessary (Reneses et al., 2003), this process of calculating deep grid connection charges is prone to political influence and lobbying. In theory, connection charges could also be negative, i.e. generators receive

7. Only hypothetical nodal pricing (Hirth et al., 2018) without lumpiness in network extension and without market power correctly reflects value differences between locations. 
Table 2. Properties of grid connection charges
CAISO
Payments serve as financial security: the TSO reimburses the interconnection customer the cost of the network upgrades over a period of up to five years. A locational signal arises from a cap of reimbursement. This cap is reviewed annually and lies at $\$ 70$ per $\mathrm{kW}$ of generator capacity (CAISO, 2019b) as of 2019; higher costs will not be reimbursed.
France New renewable energy generators are charged regionally and differentiated from contributions ("quote- parts") for grid extension (RTE, 2014). In exchange, grids are built in advance and prioritized access to the transmission system is given to these technologies. These charges are uniform within a region, but strong differences exist between regions. The instrument is purely designed for cost-recovery.
Mexico Generators only pay deep grid connection charges if the new line is not part of the national grid extension plan. In exchange for the payment, investors receive the revenues of the sale of financial transmission rights (FTR) for the corresponding line (SENER, 2018).
PJM Each generator or transmission project bears the cost for required interconnection facilities. Interconnection projects are awarded once per year to better account for shared transmission extension.
Sweden The TSO charges the costs of connection to the local DSO. These tariffs cover the cost for additional lines and substations and are levied on the causing plant operator if it can be identified (Svenska Kraftnät, 2020). As of early 2020, the exclusion of offshore wind from these charges is discussed.
Norway Deep grid connection charges are only applied in the case of radial grid connections (NVE, 2018). The customer's contribution to the investment costs is capped at a share of $50 \%$. This charge was implemented in 2019, and the old regime is in place for planned projects until 2022.

a premium for network connection in certain locations. In practice, this is, however, not the case in any of the systems reviewed. Several challenges arise from the fact that grid connection charges affect new generators. For example, sharing expenses between first and later investors is difficult, especially if subsequent investments are not predictable. In practice, the first generator finances grid infrastructure, which is then, due to its lumpiness, used by followers. This may result in a waitand-see problem with a postponing effect on investment (Swider et al., 2008). A second investment barrier results from the fact that deep grid connection charges imply high upfront costs for investors. Consequently, system costs may be larger than necessary because project developers usually face higher financing costs than regulated system operators.

\subsection{Grid usage charges}

Grid usage charges are fees for the use of the transmission and distribution system. They are regulated and designed to (at least partly) recover expenses incurred by the system operator. These can comprise capital expenses for building and maintaining grid infrastructure, and operational expenses, such as for system services, transmission losses, and congestion management. While in some systems, costs are simply passed on to consumers, other countries have developed an elaborate system of charges based on the consumer pays principle. This is the case under cost reflective charging, where the costs of each line are passed on to the consumers and generators who use it (Olmos and Pérez-Arriaga, 2009). For example, Gammons et al. (2011) found that locational transmission tariffs can lead to significantly lower overall costs in the British transmission system due to a placement of generation capacity that reduces infrastructure requirements.

Australia, India, Norway, Sweden, and the UK apply location specific grid usage charges that are paid by generators. All grid usage charges are implemented as a price instrument, but the precise design differs significantly between countries (see Table 3). Grid usage charges are imposed per MWh (Norway and Australia), per MW (India), or both (UK, Sweden). The charges are adjusted frequently, at least once a year (Australia, India, and UK) or even on a weekly basis (Norway, Sweden). Australia, Norway, and Sweden have per MWh charges that are proportional to the zonal electricity price; the level of charges is determined for each substation through the multiplication of the zonal electricity price with a site-specific factor. This factor reflects the marginal transmission 
Table 3: Characteristics of grid usage charges

\begin{tabular}{lccccc}
\hline Country & Charged per & $\begin{array}{c}\text { Spatial } \\
\text { granularity }\end{array}$ & $\begin{array}{c}\text { Premium or } \\
\text { penalty? }\end{array}$ & $\begin{array}{c}\text { Frequency of } \\
\text { adjustment }\end{array}$ & Temporal granularity \\
\hline UK & MWh and MW & 27 Zones & Both & Yearly & Time-invariant \\
Sweden & MW & 155 Substations & Penalty only & Weekly & Time-invariant (within the week) \\
Norway & MWh & 155 Substations & Both & Yearly & Multiplier on zonal price \\
Australia & MWh & $\sim 800$ Substations & Both & Weekly & Multiplier on zonal price \\
India & MWh & $\sim 1000$ Substations & Both & Yearly & Multiplier on zonal price \\
\hline
\end{tabular}

Annotation: UK's grid usage charges are specified per capacity but the calculation of charges accounts for the number of full load hours. For simplicity, we classify them as capacity-based instruments in the following.

Sources: (AEMO, 2019; CERC, 2018; National Grid, 2018; NVE, 2018; Svenska Kraftnät 2019)

losses and sometimes the cost of grid congestion and it differs by location. Under such a design, higher signals arise for technologies that generate electricity during high price periods (peakers) and weaker signals for technologies of which the generation coincides with low prices (e.g. wind and solar). The spatial resolution of charges varies significantly: the UK is split into 27 zones, Norway and Australia charge transmission fees on a substation-level, and charges in Sweden depend on the geographical latitude. In India, charges are calculated by node, and then aggregated per utility. In Australia, Norway, Sweden, and the UK, grid usage charges can be negative (i.e. generators receive payments at certain locations). In all cases in our sample, grid usage charges are determined ex-ante and affect new and existing generators.

Allocating grid costs according to the consumer pays principle has proven difficult in practice because there is no indisputable method to compute the electrical utilization of lines by agents (Olmos and Pérez-Arriaga, 2009). Hence, especially in distribution grids, proxies are used to maintain transparency and reproducibility, which reduces the accuracy of the instrument. In contrast to grid connection charges, grid usage charges also affect existing generators. Thus, changes to the tariff design imply a risk for generators. For instance, new transmission lines and investment in generation have caused locational benefits to fall by large margins in Australia. More specifically, location-specific marginal loss factors, which are proportional to generator's revenues, have decreased by up to $11 \%$ on average in certain regions from 2018 to 2019 (AEMO, 2019). This, in turn, had material financial implications that were often unforeseen by existing and intending market participants, which highlights the importance of predictable and transparent grid expansion plans.

\subsection{Capacity mechanisms}

Capacity mechanisms remunerate plant operators for providing capacity to the power system. One problem common to many capacity mechanisms results from a uniform incentive across the system. Nieto and Fraser (2007) emphasize that this lack of locational granularity may worsen capacity and transmission problems in specific locales, even while it resolves the capacity problem in the aggregate. Some capacity mechanisms therefore have a location-specific component (i.e. the mechanism incentivizes capacity on a sub-system scale).

Among the selected systems, Chile, CAISO, France, Germany and PJM have a location specific capacity mechanism (Table 4) whereby most apply quantity-based mechanisms. In PJM and CAISO, load serving entities are obliged to contract for firm capacity at a sub-system level. While an organized market in PJM facilitates this process (PJM, 2019), CAISO's load serving entities are bound to contract capacity directly (CAISO, 2019a). In France, a tender was set up on top of a 
Table 4: Characteristics of capacity mechanisms

\begin{tabular}{lcccc}
\hline & Regulator sets & Spatial granularity & Product duration & Ex-ante or ex-post \\
\hline Chile & Price & 49 nodes & 6 months & Ex-post \\
CAISO & Quantity & 10 areas & undefined & Ex-ante \\
France & Quantity & 1 node (single plant) & 20 years & Ex-ante \\
Germany & Quantity & 4 areas & 10 years & Ex-ante \\
PJM & Quantity & 20 sub-systems & 1 year & Ex-ante \\
\hline
\end{tabular}

Sources: (CRE, 2014; CAISO, 2019a; PJM, 2019; CNE, 2018; Tennet 2019)

non-location-specific capacity market to build a new power plant in the import-constrained region Brittany $^{8}$ (CRE, 2014). Germany's local capacity procurement by tender ${ }^{9}$ incentivizes the construction of four new power plants in the south of the country. ${ }^{10}$ These plants will provide redispatch services to grid operators and do not sell electricity on the wholesale market. By contrast to all these systems, Chile applies a price-based capacity mechanism. The Chilean energy commission determines nodal capacity prices as the cost of investing in a diesel-fired turbine that runs at system's peak demand. All generators are remunerated based on their historical availability at peak demand (ex-post). While the geographic granularity of the capacity payments coincides with that of the energy market in Chile, this is not the case in the US, where CAISO and PJM employ nodal energy markets but zonal capacity markets.

By their very nature, capacity mechanisms are specified per MW and are therefore time-invariant instruments. Their predictability varies significantly. Tenders in France and Germany offer high investment security due to their long duration; the other capacity mechanisms provide less investment security due to shorter contract durations and higher price volatility. Whereas the Chilean approach of a price-based instrument provides more price-security, the uncertainty of contracted capacity undermines the reliability objective of the instrument (Nieto and Fraser, 2007). All instruments are implemented as premiums that awards both new and existing generators.

\subsection{Renewable energy support schemes}

Globally, 135 countries use support schemes for the deployment of renewable energy (REN21, 2019). Renewable energy sources have outpaced conventional capacity in terms of newly added capacity since 2014 (IRENA, 2019), and many observers expect most future generation investment to concentrate on renewable energy sources (Bloomberg New Energy Finance, 2019). Support schemes can have very different forms: feed-in tariffs, renewable portfolio standards, and subsidized loans are just a few examples. While some of these support schemes are not location-specific, others are. The effect of renewable support schemes on the spatial distribution of new generators has been discussed among others by Wagner (2019), Pechan (2017) and Schmidt et al. (2013).

We have identified location-specific renewable support schemes in Germany and Mexico (see Table 5). ${ }^{11}$ Locational signals either result from price discrimination in the winner selection process of auctions (e.g. premiums or penalties in certain regions) or stem from quantity regulation (e.g.

8. The winning project was a $450 \mathrm{MW}$ combined cycle gas turbine plant located in Landivisiau, Brittany. The region was specified in the tender, but no site was predeveloped.

9. In German: Besondere netztechnische Betriebsmittel

10. The German network reserve was excluded because it only encompasses existing power plants and therefore does not provide an investment incentive.

11. Net metering tariffs are one form of support scheme. Some utilities, e.g. in Austin (Texas) offer tariffs with a locational component. We excluded them from our analysis because no uniform regulation on these tariffs (Jahn et al., 2019). 
Table 5: Characteristics of renewable support schemes

\begin{tabular}{llllr}
\hline & Type & $\begin{array}{c}\text { Spatial } \\
\text { granularity }\end{array}$ & Technologies & $\begin{array}{c}\text { Temporal } \\
\text { granularity }\end{array}$ \\
\hline Mexico & Premium and penalty & 53 zones & $\begin{array}{c}\text { All renewable energy } \\
\text { sources, nuclear, CHP } \\
\text { Wind }\end{array}$ & Time-invariant \\
$\begin{array}{l}\text { Germany } \\
\quad \text { Referenzertragsmodell) }\end{array}$ & Premium and penalty & Plant specific & Time-invariant \\
$\begin{array}{c}\text { Germany } \\
(\text { Verteilernetzkomponente) }\end{array}$ & Penalty & 98 districts & Wind and solar & Time-invariant \\
Germany (Netzausbaugebiet) & Quantity cap & 2 zones & Wind & Time-invariant \\
\hline
\end{tabular}

Sources: (IRENA, 2017; BMWi, 2019; 2017; FA Wind 2019)

floors for certain regions). In Mexico and Germany, the selection of winning bids in auctions has a locational component in some cases. The Mexican auction for clean energy aims to reflect the costs of locations designated for new installations. Price bids are adjusted by locational premiums and penalties; projects in supply-constrained regions get awarded at higher bid prices and vice versa. These locational markers are determined ex-ante through an optimization model that maximizes the economic surplus of additional generation for each node. A similar approach has been chosen for two types of renewable energy auctions in Germany. First, in onshore wind auctions, adjustment factors for each location are determined according to the average wind speed ("Referenzertragsmodell"). Although this instrument does not explicitly account for grid constraints, it has a similar effect given that wind speeds and grid constraints arise in similar regions. Second, in technology-neutral renewable auctions, projects are penalized when connected to distribution grids where renewable feed-in exceeds local demand ("Verteilernetzkomponente"). The penalties depend on the already locally installed capacity and differ for wind and solar. Another locational instrument in Germany is the limitation of wind deployment for the most grid-constrained regions through a quantity cap in the auction design ("Netzausbaugebiet"). When binding, this constraint results in lower support levels in the constrained area and may lead to higher support in the unconstrained area. Hence, Germany uses three locational mechanisms in its support schemes.

All four locational renewable support schemes are energy-based instruments; premiums and penalties are paid per MWh generated. The locational marker has no temporal granularity and is time invariant. In all price instruments, the determination of the locational signal occurs in a transparent manner ex-ante and is fixed for 15 to 20 years. They therefore provide one of the most certain signals. A major drawback of locational incentives in renewable energy support schemes is that only new and subsidized renewable energy sources are targeted. Market-driven renewable investment as well as conventional generation and storage remain unaffected by the instrument. This limited scope may lead to a cost-inefficient allocation of technologies.

\subsection{Incidence of instruments across our sample}

Summarizing the findings of our empirical review yields four interesting insights (see Table 6). First, each of the twelve power systems reviewed uses at least one locational instrument. Second, most power systems actually employ multiple instruments. Sweden, for example, has split its electricity market into four zones, applies deep connection charges and has location-specific grid usages charges per $\mathrm{kW}$ and location-specific charges per MWh. PJM and CAISO apply locational marginal pricing, deep connection charges, and a zonal capacity market. Germany has three distinct mechanisms within its renewables support scheme in addition to a less significant capacity instrument. Third, most power systems that have spatial granular markets, use additional instruments 
Table 6: Locational components in instruments applicable to generators

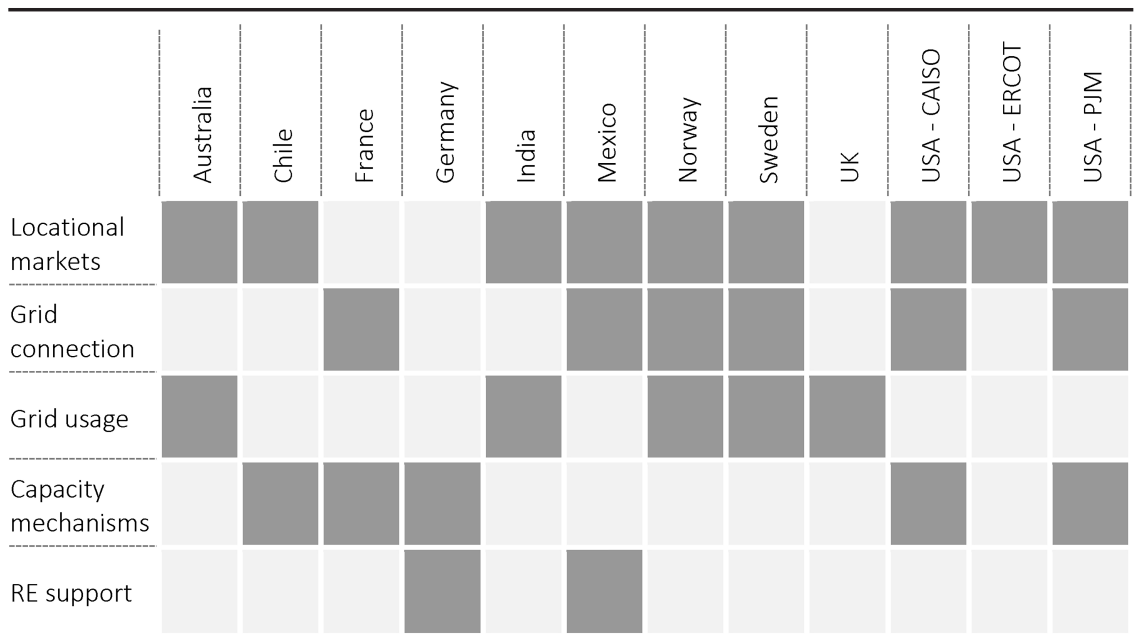

Locational instrument

No locational instrument

Key point: Every reviewed power system employs at least one locational instrument. Strikingly, even most systems with locational electricity markets use additional instruments. Further information and sources are listed in Table A.1.

to steer investment. Among these, some of the countries (Australia, Norway and Sweden) implemented energy-based grid usage charges that provide additional (distorting) dispatch incentives. Finally, no instrument is used across all power systems.

\section{QUANTIFICATION OF INSTRUMENTS}

In section 2, we defined the strength of locational signal as the difference in revenue (or cost) it induces on generators between locations. A high or strong signal leads to large differences in revenue (or cost) between locations and a low or weak signal in small differences. The strength thus greatly matters for investment decisions. In this section, we propose and apply a simple method to quantify and compare the strength of the 28 instruments where data is available.

\subsection{Quantifying the signals in original units of measurement}

The presented instruments provide financial incentives, and we determine the magnitude of additional revenues and costs arising from them. We proxy the strength of an instrument, $d$, as the highest difference in revenues (or costs) that it induces:

$$
d=S_{\max }-S_{\min }
$$

where $s_{\max }$ is the value of the signal at the location where it is highest and $s_{\min }$ where it is lowest. Hence, $d$ is the maximal impact the instrument can have among two alternative locations for an investment. This approach can be used to compare highly diverse instruments by isolating the locational effect from the overall level of payments and revenues. 
To illustrate the approach, we exemplarily quantify the locational signal that results from British Transmission Network Use of System charges (TNUoS) on onshore wind energy ${ }^{12}$. The highest charges apply to the region of Glenglass in North Scotland and the lowest (negative) charges in Central London. TNUoS are reported in pounds per kW. From Eq. (1), we obtain: ${ }^{13}$

$$
\begin{aligned}
& S_{\text {max }}=30 £ / \mathrm{kW} \cdot \mathrm{a} \\
& s_{\text {min }}=-8 £ / \mathrm{kW} \cdot \mathrm{a} \\
& d=s_{\text {max }}-S_{\text {min }}=38 £ / \mathrm{kW} \cdot \mathrm{a} \approx 43 € / \mathrm{kW} \cdot \mathrm{a}
\end{aligned}
$$

Similarly, this metric was applied to our sample of instruments. To maintain comparability, we quantified all signals for the year 2018 when possible. $d$ is expressed in EUR ${ }^{14}$ per kWh or per MW depending on how the instrument is specified. For time-variant instruments, we use annual averages to determine the most expensive and the cheapest location. The locational signal for quantity-based instruments, such as regional capacity limits for renewables, is not explicit. We then use the maximal spread of the instrument between constrained regions. Table 7 shows that the magnitude of signals $d$ varies strongly. A direct comparison between instruments is difficult due to the diversity of units. We therefore estimated the strength of all signals in an equivalent energy charge (in EUR per $\mathrm{MWh}$ ), which is discussed in the next subsection.

\subsection{Conversion into Euro per MWh}

To convert annual capacity-based payments, such as grid usage charges specified per installed capacity, into equivalent payments $\left(c_{\text {per MWh }}\right)$ for every MWh generated, annual costs $\left(c_{\text {annual, per MW }}\right)$ are divided by the number of full load hours $(F L H)$ (Eq. (2)). Since the conversion of per-kW signals into per-MWh terms depends on the capacity factor, and some instruments are technology-specific, we use two exemplary cases: (i) a combined cycle gas turbine with 5000 full load hours (capacity factor of 57\%) and (ii) onshore wind power with 3000 full load hours (34\%).

$$
c_{\text {per } M W h}=\frac{c_{\text {annual, } \text { per } M W}}{F L H}
$$

We convert nonrecurring payments such as grid connection charges into an annuity over the expected lifetime (Eq. (3)). The annuity factor itself depends on lifetime $n$ and weighted average cost of capital WACC. For both technologies, we assume a $W A C C$ of $5 \%$ and a lifetime $n$ of 25 years.

$$
c_{\text {annual, per } M W}=c_{\text {lifetime, per } M W} \cdot \frac{W A C C}{1-(1+W A C C)^{-n}}
$$

Revisiting the British TNUoS, Eq. 2 can be used to express $d$ of 43 EUR per kW (see 4.1) as an equivalent energy charge. Assuming 3000 full load hours for wind generation, we obtain an equivalent of around 14 EUR per MWh. The British TNUoS is a special case since charges are expressed per capacity but also depend on technology type and the capacity factor (National Grid, 2018). Therefore, not only the equivalent energy charge but also the capacity charges differ for wind and gas turbines (Table 8).

12. Unlike all other instruments, TNUoS are specified per capacity but also depend on the capacity factor. We assume 3000 full load hours and utilize the level of charges applicable in 2018/2019 (National Grid, 2018).

13. We distinguish costs of energy (e.g. $€ / \mathrm{MWh})$ and yearly costs of capacity (e.g. $€ / \mathrm{kW} \cdot \mathrm{a})$ by notation.

14. We use the exchange rate as of 01.01.2019 to convert costs into EUR. 
Table 7: Strength of locational signals applicable to generators

\begin{tabular}{|c|c|c|c|c|c|c|c|c|c|c|c|c|}
\hline & 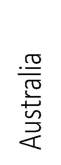 & $\frac{\mathscr{e}}{\frac{\mathscr{C}}{\leftrightarrows}}$ & 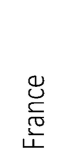 & 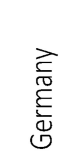 & $\frac{\text { 음 }}{\underline{\underline{C}}}$ & $\frac{.0}{\frac{0}{x}}$ & $\begin{array}{l}\text { do } \\
\text { 交 } \\
\text { 之 }\end{array}$ & $\begin{array}{l}\frac{c}{d} \\
\frac{\Phi}{0} \\
\sum\end{array}$ & 弚 & 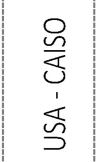 & 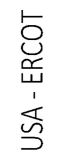 & 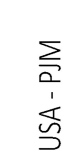 \\
\hline $\begin{array}{l}\text { Locational mar- } \\
\text { kets (€/MWh) }\end{array}$ & 25 & 9 & & & 0 & 13 & 1 & 2 & & 14 & 19 & 21 \\
\hline $\begin{array}{l}\text { Grid connection } \\
(€ / \mathrm{kW} \cdot \mathrm{a})\end{array}$ & & & 70 & & & $*$ & $*$ & $63^{*}$ & & $\begin{array}{l}1080 \\
*\end{array}$ & & $540^{*}$ \\
\hline $\begin{array}{l}\text { Grid usage } \\
(€ / M W h)\end{array}$ & & & & & & & 8 & 3 & & & & \\
\hline $\begin{array}{l}\text { Grid usage } \\
(€ / \mathrm{kW} \cdot \mathrm{a})\end{array}$ & 14 & & & & 36 & & & 3 & 43 & & & \\
\hline $\begin{array}{l}\text { Capacity mecha- } \\
\text { nisms }(€ / \mathrm{kW} \cdot \mathrm{a})\end{array}$ & & 21 & 94 & $*$ & & & & & & * & & 31 \\
\hline $\begin{array}{l}\text { RE support } \\
(€ / M W h)\end{array}$ & & & & 32 & & 11 & & & & & & \\
\hline $\begin{array}{l}\text { * no or poor data } \\
\text { availability }\end{array}$ & & & & $\begin{array}{l}\text { Locat } \\
\text { instru }\end{array}$ & $\begin{array}{l}\text { nal } \\
\text { nent }\end{array}$ & & & & $\begin{array}{l}\text { No lo } \\
\text { instru }\end{array}$ & $\begin{array}{l}\text { cationa } \\
\text { ment }\end{array}$ & & \\
\hline
\end{tabular}

Annotations: Further information and sources are listed in Table A.1. The tile for Germany's renewable support only covers the locational signal of the wind auction adjustment factor ("Referenzertragsmodell"). The penalty in overloaded distribution grids ("Verteilernetzkomponente") results in a maximal signal of $8.8 € / \mathrm{MWh}$ (not represented in Table 7). Because the locations with highest and lowest signal do not coincide, signals cannot be superposed. Germany's quantity constraint ("Netzausbaugebiet") was never binding in 2018 and did not result in a locational signal.

Table 8: Strength of the locational signal of TNUoS expressed per unit of capacity and per unit of generation

\begin{tabular}{llcc}
\hline & & $€ / \mathrm{kW}$ p.a. & $€ /$ MWh \\
\hline Renewable & Wind power (3000 FLH) & 43 & 14 \\
Mid-load & Combined cycle gas turbine (5000 FLH) & 34 & 7 \\
\hline
\end{tabular}

\subsection{Findings of the quantification}

Tables 9 and 10 display the highest value (or cost) difference each instrument induces for a combined cycle plant and a wind power turbine. Tables 9 and 10 are expressed in EUR per MWh, comparable to the levelized cost of electricity. The same results expressed in EUR per MW are shown in the appendix (Tables A.2 and A.3), which is closer to the notion of repaying fixed costs. Values for gas and wind diverge due to different capacity factors and because some instruments are technology specific. We find that in countries that apply several instruments, the locations where the signal is highest and lowest are not always the same across instruments. In our sample, this is the case in Australia, Chile and PJM. In these systems, the combined signal of instruments (shown in the bottom row of tables 9 and 10) is lower than the sum of the individual signals, which implies signals are (partly) directed toward different directions. ${ }^{15}$

15. Data availability for grid connection charges was weak, and we did not account for opposing locational effects between these and other instruments when calculating the combined effect. 
Table 9: Highest value (or cost) differences of locational signals for combined cycle gas power plant (expressed in EUR per MWh)

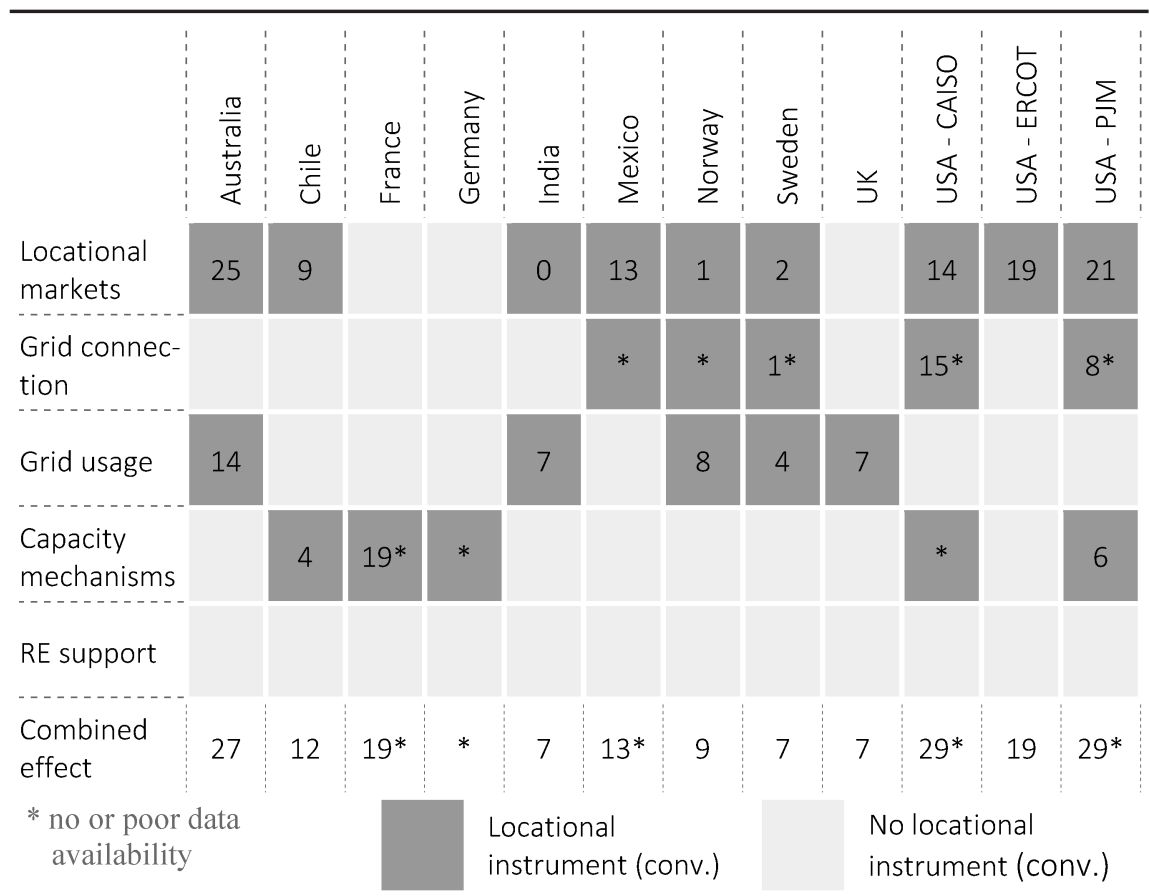

Table 10: Highest value (or cost) differences of locational signals for wind generation (expressed in EUR per MWh)

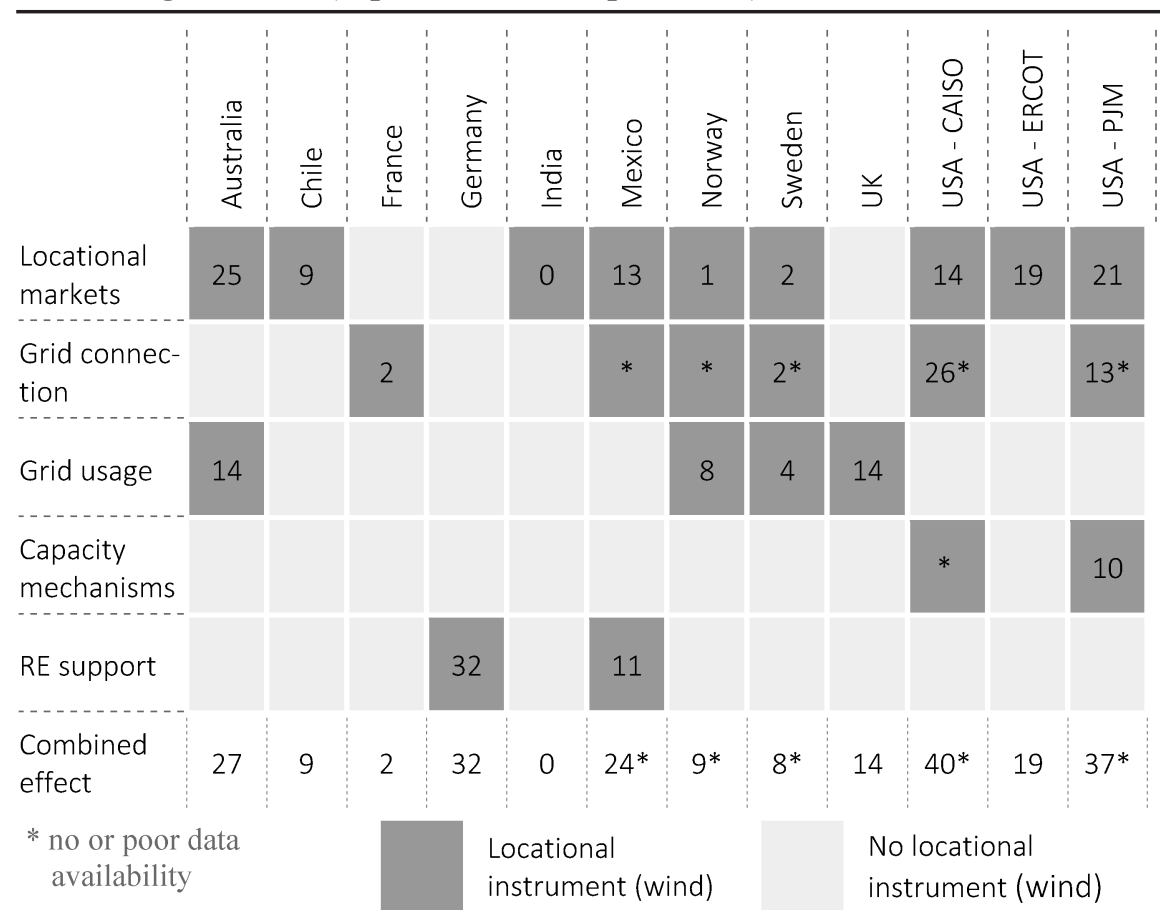


Most of the instruments we studied apply to gas-fired power generation, except for support schemes and certain grid fees (Table 9). Three points are worth noting. First, the magnitude of instruments varies significantly, with some having virtually no effect and others introducing a spread of around 20 EUR per MWh. Secondly, the overall impact is very limited in some countries, where not a single strong instrument exists (e.g., in Sweden, Norway, UK and India) and very large in others (e.g., in Australia and PJM). Thirdly, each class of instruments contains examples with very weak signals and others where signals are very strong. This indicates no instrument class always results in weak signals while another persistently results in strong signals.

Wind energy is affected by all instruments apart from some capacity mechanisms and the grid usage charges in India. The general findings for gas-fired generation also hold true for wind. In addition, we observe that all instruments originally specified per unit of installed capacity have a stronger effect per energy produced for wind than for gas. This can be explained by the lower capacity factor of wind, which results in higher induced value differences of capacity-based instruments when expressed per energy (see Eq. 2). The locational signal emerging from renewable support schemes turns out to be relatively strong compared to other instruments. An even higher incentive than shown in the table arose in Mexico's first clean energy auctions in 2016, where signals of winning bids had a maximal locational spread of 38 EUR per MWh (IRENA, 2017). ${ }^{16}$ For both technologies, results for grid connection charges should be treated with care, since data availability is poor.

\subsection{Discussion of results}

When interpreting results, it is important to acknowledge that a low locational signal either indicates that it does not fully reflect the marginal difference in value of generation between locations (i.e. its marginal transmission related costs), or that this difference is just as small as indicated by the signal. By analogy, a high locational signal does not necessary imply that future investment should or is likely to occur at signaled locations. High differences in construction costs or resource availability between locations can explain why even comparatively strong locational signals may have little impact on investment decisions.

To fully appraise the magnitude of the various instruments, each needs to be compared to a signal that internalizes all transmission related costs and leads to the cost-optimal allocation of generators. As discussed in the introduction, the cost-efficient signal depends on system specific costs and hence varies between power systems.

Hypothetical nodal prices (Maurer, Zimmer, and Hirth, 2018) without market power and without lumpiness in grid investments reflect these value differences in a long-term equilibrium. Pérez Arriaga et al. (1995) show that these (strong) assumptions are not fulfilled in real-world nodal power systems. In practice, only $20-30 \%$ of total grid costs are recovered from congestion rents due to a structural overinvestment in transmission infrastructure, resulting from discrete transmission extension and reliability constraints (owing to imperfect foresight). Thus, the observed strength of nodal electricity markets is not a good proxy for the optimal, cost-efficient value difference.

One indicator helpful in interpreting the strength of instruments is the difference in generation costs between locations. For base-load technologies, these are an upper limit for the cost-efficient signal; a higher signal (which ideally reflects the marginal transmission costs) would imply total cost can be reduced by relocating generators despite higher generation costs. ${ }^{17}$ In Germany, the difference in the levelized cost of wind generation varies for example between 40 EUR per MWh in

16. The locational markers in all (not rewarded) areas even differed by 70 EUR per MWh.

17. For non-base load plants, time profiles of generation matter and such an upper bound does not hold. 
the north and 70 EUR per MWh for the same plant type in the south, which has a similar magnitude as the locational signal of the renewable support scheme.

A second indicator to compare the signals' strength to are the levelized costs of electricity generation. Locational signals in the range of 20 EUR per MWh are quite significant compared to levelized costs of combined cycle plants of 64-72 EUR per MWh in Europe ${ }^{18}$.

The approach employed in this study was to analyze the instruments' impact at the two most extreme areas. This is a helpful proxy to better understand the potential impact of each instrument. However, this metric does not provide information about any other location, and it is sensitive to outlying values. A distribution function of an instrument's strength, as opposed to a single scalar, would provide richer information, but could not be constructed due to a lack of data. Given the number of instruments, such quantification would also be difficult to compare. Finally, we emphasize again that the signal's magnitude is only one out of many indicators that determine whether an instrument affects the siting decision of new capacity.

\section{SUMMARY AND CONCLUSIONS}

Well-designed locational signals encourage generators to consider transmission- and congestion-related costs in their siting decision. This paper discusses the need for and trade-offs between instrument types and designs. To achieve this aim, we cluster instruments into five groups: locational electricity markets, grid connection charges, grid usage charges, capacity mechanisms, and renewable energy support schemes. Our analysis highlights that all twelve reviewed power systems employ at least one locational instrument. Most systems, including power systems that implemented locational electricity markets, use multiple instruments in parallel.

The design of an instrument determines whether it affects the siting decision of new generators. We identify ten relevant design elements, which often entail trade-offs. Due to these tradeoffs, all instruments have some drawbacks. The three major shortcomings of many instruments are unpredictability of future regulatory changes and insufficient spatial and temporal granularity of signals. First, predictable signals reduce investor's risks and are therefore likely to have a larger impact on investment decisions. To improve the predictability, transparency in methods, models, and assumptions is key. In practice, however, the calibration methodology of most instruments is opaque. Predictability of future cash flows is highest for deep grid connection charges, most renewable support schemes, and some capacity mechanisms due to long contract durations. Second, the spatial granularity varies significantly between instruments. At a minimum, it should reflect relevant network bottlenecks. Third, the temporal resolution of most instruments is low, implying these instruments do not reflect changing marginal value differences over time. The finding that there is no "silver bullet" instrument matches with the observation that no instrument is used across all countries.

The quantification of instruments reveals significant variation in their strength. Quantitative estimates suggest that the signals' magnitude differs significantly across systems. While the difference between locations where the signal is highest and lowest is small for some instruments, for others it is around 20 EUR per MWh. Such a difference is significant when compared to the levelized costs of combined cycle plants of 64-72 EUR per MWh in Europe.

18. Own calculation based on assumptions for CCGT stated in section 4.2 and cost data from the World Energy Outlook, 2018 (IEA, 2019) 


\section{ACKNOWLEDGMENTS}

This work was supported by the Energy Transition Hub, a collaborative venture supported by the German Federal Ministry of Education and Research under project number 03EK3046F. The funders had no role in study design, analysis, or preparation of the manuscript.

We would like to thank Ingmar Schlecht, Oliver Ruhnau, Laima Eicke, Raffaele Sgarlato, Lars Stephan, Dylan McConnell, Stacey Crowley, Juan Pablo Carvallo, Kenneth Van den Bergh, Iolanda Saviuc, Diana Chklar, Markus Wypior, Mårten Bergman, Andreas Jahn, the participants of the workshop "Locational Investment Signals" and of the YEEES seminar Leuven, and two anonymous reviewers for valuable comments, expert insights and feedback. All remaining errors remain our responsibility.

\section{REFERENCES}

AEMO (2019). "Marginal Loss Factors for the 2019-20 Financial Year.” https://www.aemo.com.au.

Alayo, Hans, Marcos J. Rider, and Javier Contreras (2017). "Economic Externalities in Transmission Network Expansion Planning.” Energy Economics 68 (October): 109-15. https://doi.org/10.1016/j.eneco.2017.09.018.

Ambrosius, M., J. Egerer, A. V. Grimm, and A. van der Weijde (2019). “The Role of Expectations for Market Design—on Structural Regulatory Uncertainty in Electricity Markets.” Working Paper. Faculty of Economics. https://doi.org/10.17863/ CAM.40107.

Bigerna, Simona, Carlo Andrea Bollino, and Paolo Polinori (2016). "Renewable Energy and Market Power in the Italian Electricity Market.” The Energy Journal 37(01). https://doi.org/10.5547/01956574.37.SI2.ppol.

Bird, Lori, Debra Lew, Michael Milligan, E. Maria Carlini, Ana Estanqueiro, Damian Flynn, Emilio Gomez-Lazaro, et al (2016). "Wind and Solar Energy Curtailment: A Review of International Experience." Renewable and Sustainable Energy Reviews 65(November): 577-86. https://doi.org/10.1016/j.rser.2016.06.082.

Bloomberg New Energy Finance (2019). “New Energy Outlook 2019.” https://about.bnef.com/new-energy-outlook/.

BMWi (2017). "Verordnung Zu Den Gemeinsamen Ausschreibungen Für Windenergieanlagen an Land Und Solaranlagen." https://www.bmwi.de/.

(2019). "Gesetz Für Den Ausbau Erneuerbarer Energien (Erneuerbare-Energien-Gesetz - EEG 2017).” http://www. gesetze-im-internet.de/eeg_2014/EEG_2017.pdf.

BNetzA (2017). “Gemeinsame Ausschreibungen von Windenergieanlagen an Land Und Solaranlagen.” 2017. https://www. bundesnetzagentur.de/DE/Sachgebiete/ElektrizitaetundGas/Unternehmen_Institutionen/Ausschreibungen/Technologieuebergreifend/GemeinsAusschr_node.html.

Brunekreeft, Gert, Karsten Neuhoff, and David Newbery (2005). "Electricity Transmission: An Overview of the Current Debate.” Utilities Policy 13 (2): 73-93. https://doi.org/10.1016/j.jup.2004.12.002.

CAISO (2019a). “Annual Report on Market Issues and Performance 2018.” 2019. http://www.caiso.com/Documents/ 2018AnnualReportonMarketIssuesandPerformance.pdf.

_ (2019b). "Fifth Replacement FERC Electric Tariff.” 2019. http://www.caiso.com/Documents/ConformedTariff-asofApr1-2019.pdf.

CERC (2018). "Slab Rates for PoC Charges \& Losses 2018 - Order No. L-1/44/2010-CERC.”.

CNE (2018). "Fijación de Precios de Nudo Promedio Del Systema Eléctrico Nacional.” 2018. https://www.cne.cl/.

CRE (2014). "Landivisiau: Informations Complémentaires Sur Le Contexte Du Projet.” 2014. http://pref29.alkante.com/ sit_1_ALK/upload/actu/1301/document_reponse_AE.pdf.

Deilen, Caroline, Tim Felling, Robin Leisen, and Christoph Weber (2019). "Evaluation of Risks for Electricity Generation Companies through Reconfiguration of Bidding Zones in Extended Central Western Europe.” The Energy Journal 40(01). https://doi.org/10.5547/01956574.40.SI1.cdei.

ENTSO-E (2018). "Overview of Transmission Tariffs in Europe: Synthesis 2018.” https://docstore.entsoe.eu/Documents/ MC\%20documents/TTO_Synthesis_2018.pdf.

FA Wind (2019). “8. Ausschreibung Für Windenergieanlagen an Land.” 2019. https://www.fachagentur-windenergie.de.

Gammons, Sean, Richard Druce, and Goran Strbac (2011). "Locational Transmission Charging in Decarbonised Power Markets." Nera Economic Consulting. 
Green, Richard (2003). “Cost Recovery and the Efficient Development of the Grid.” In Transport Pricing of Electricity Networks, by François Lévêque, 137-53. Boston, MA: Springer US. https://doi.org/10.1007/978-1-4757-3756-1_5.

(2004). "Electricity Transmission Pricing: How Much Does It Cost to Get It Wrong?" http://ceepr.mit.edu/files/ papers/2004-020.pdf.

Hadush, Samson, Patrik Buijs, and Ronnie Belmans (2011). "Locational Signals in Electricity Market Design: Do They Really Matter?” In . Zagreb, Croatia. https://doi.org/10.1109/EEM.2011.5953086.

Hirth, Lion, Ingmar Schlecht, Christoph Weber Maurer, and Bernd Tersteegen (2018). "Zusammenspiel von Markt und Netz im Stromsystem.” https:/www.bmwi.de/Redaktion/DE/Publikationen/Studien/zusammenspiel-von-markt-und-netz-imstromsystem.html.

Hogan, William (1999). “Transmission Congestion: The Nodal-Zonal Debate Revisited.” https://sites.hks.harvard.edu/fs/ whogan/nezn0227.pdf.

Holmberg, Par, and Ewa Lazarczyk (2015). “Comparison of Congestion Management Techniques: Nodal, Zonal and Discriminatory Pricing.” The Energy Journal 36(2). https://doi.org/10.5547/01956574.36.2.7.

IEA (2019). "WEO 2018 Assumptions." https://www.iea.org/weo/weomodel/.

IRENA (2017). Renewable Energy Auctions: Analysing 2016. Abu Dhabi.

(2019). "Renewable Capacity Highlights.” Renewable Capacity Statistics 2019. https://www.irena.org/.

Jahn, Andreas, Megan O’Reilly, and Matthias Deutsch (2019). "Photovoltaik-Eigenversorgung: Erfahrungen aus den NetEnergy-Metering-Programmen der USA."

Joskow, Paul L. (2008). “Capacity Payments in Imperfect Electricity Markets: Need and Design.” Utilities Policy 16(3): 159-70. https://doi.org/10.1016/j.jup.2007.10.003.

Keller, Katja, and Jörg Wild (2004). "Long-Term Investment in Electricity: A Trade-off between Co-Ordination and Competition?” Utilities Policy 12(4): 243-51. https://doi.org/10.1016/j.jup.2004.03.002.

Maurer, Christoph, Christian Zimmer, and Lion Hirth (2018). "Nodale Und Zonale Strompreissysteme Im Vergleich.” https:// www.bmwi.de/.

National Grid (2018). "Final Tariffs for 2018/19.” https://www.nationalgrid.com.

Neary, J.P., and K.W.S. Roberts (1980). "The Theory of Household Behaviour under Rationing." European Economic Review 13(1): 25-42. https://doi.org/10.1016/0014-2921(80)90045-8.

Neuhoff, Karsten, Julian Barquin, Janusz W. Bialek, Rodney Boyd, Chris J. Dent, Francisco Echavarren, Thilo Grau, et al. (2013). "Renewable Electric Energy Integration: Quantifying the Value of Design of Markets for International Transmission Capacity." Energy Economics 40(November): 760-72. https://doi.org/10.1016/j.eneco.2013.09.004.

Nieto, Amparo D., and Hamish Fraser (2007). "Locational Electricity Capacity Markets: Alternatives to Restore the Missing Signals.” The Electricity Journal 20(2): 10-26. https://doi.org/10.1016/j.tej.2006.12.006.

Nikogosian, Vigen, Baris Özalay, Lara Lück, Maik Schönefeld, Hao Chang, and Julian Sprey (2019). "Regionale Steuerung zur Synchronisation von EE- und Netzausbau." https://www.e-bridge.de.

NVE (2018). “The Norwegian Power System. Grid Connection and Licensing.” 2018. http://publikasjoner.nve.no/.

Olmos, Luis, and Ignacio J. Pérez-Arriaga (2009). "A Comprehensive Approach for Computation and Implementation of Efficient Electricity Transmission Network Charges.” Energy Policy 37. https://doi.org/10.1016/j.enpol.2009.07.051.

Pechan, A. (2017). "Where Do All the Windmills Go? Influence of the Institutional Setting on the Spatial Distribution of Renewable Energy Installation.” Energy Economics 65(June): 75-86. https://doi.org/10.1016/j.eneco.2017.04.034.

Pérez-Arriaga, Ignacio J., ed. (2013). Regulation of the Power Sector. Power Systems. London: Springer London. https://doi. org/10.1007/978-1-4471-5034-3.

Pérez-Arriaga, Ignacio J., and Yves Smeers (2003). “Pricing of Electrical Transmission and Distribution Networks.” In Transport Pricing of Electricity Networks, 175-204. Boston/Dordrecht/London: Francois Lévêque. DOI: 10.1007/978-1-47573756-1.

Pérez-Arriaga, Ignacio José, Francisco Javier Rubio Odériz, Juan Felipe Puerta Guitérrez, José Arcélus Ogando, and Javier Martin (1995). "Marginal Pricing of Transmission Services. An Analysis of Cost Recovery" IEEE Transactions on Power Systems (1): 65-72. https://doi.org/10.1109/59.373981.

PJM (2019). "PJM Learning Center - Capacity Market (RPM).” https://learn.pjm.com/.

REN21 (2019). “Renewables 2019 Global Status Report.” https://www.ren21.net/gsr-2019.

RTE (2014). “Accueil Des Énergies Renouvelables Sur Le Réseau: RTE Se Mobilise.” https://www.rte-france.com/.

Schmidt, J., G. Lehecka, V. Gass, and E. Schmid (2013). "Where the Wind Blows: Assessing the Effect of Fixed and Premium Based Feed-in Tariffs on the Spatial Diversification of Wind Turbines.” Energy Economics 40 (November): 269-76. https:// doi.org/10.1016/j.eneco.2013.07.004.

Schweppe, Fred C., Michael C. Caramanis, Richard D. Tabors, and Roger E. Bohn (1988). Spot Pricing of Electricity. Power Electronics and Power Systems. Boston, MA: Springer US. https://doi.org/10.1007/978-1-4613-1683-1. 
SENER (2018). "Manual para la Interconexión de Centrales Eléctricas y Conexión de Centros de Carga." http://www. diputados.gob.mx.

Svenska Kraftnät (2019). “Tariff/Charges | Svenska Kraftnät.” https://www.svk.se.

(2020). "Interview with Santiago Piva on the 07. February 2020."

Swider, Derk J., Luuk Beurskens, Sarah Davidson, John Twidell, Jurek Pyrko, Wolfgang Prüggler, Hans Auer, Katarina Vertin, and Romualdas Skema (2008). "Conditions and Costs for Renewables Electricity Grid Connection: Examples in Europe.” Renewable Energy 33(8): 1832-42. https://doi.org/10.1016/j.renene.2007.11.005.

Tennet (2019). "Besondere netztechnische Betriebsmittel: TenneT erteilt Zuschlag an Uniper.” https://www.tennet.eu/.

Vogel, Philip (2009). "Efficient Investment Signals for Distributed Generation.” Energy Policy 37(9): 3665-72. https://doi. org/10.1016/j.enpol.2009.04.053.

Wagner, Johannes (2019). "Grid Investment and Support Schemes for Renewable Electricity Generation.” The Energy Journal 40(2). https://doi.org/10.5547/01956574.40.2.jwag. 


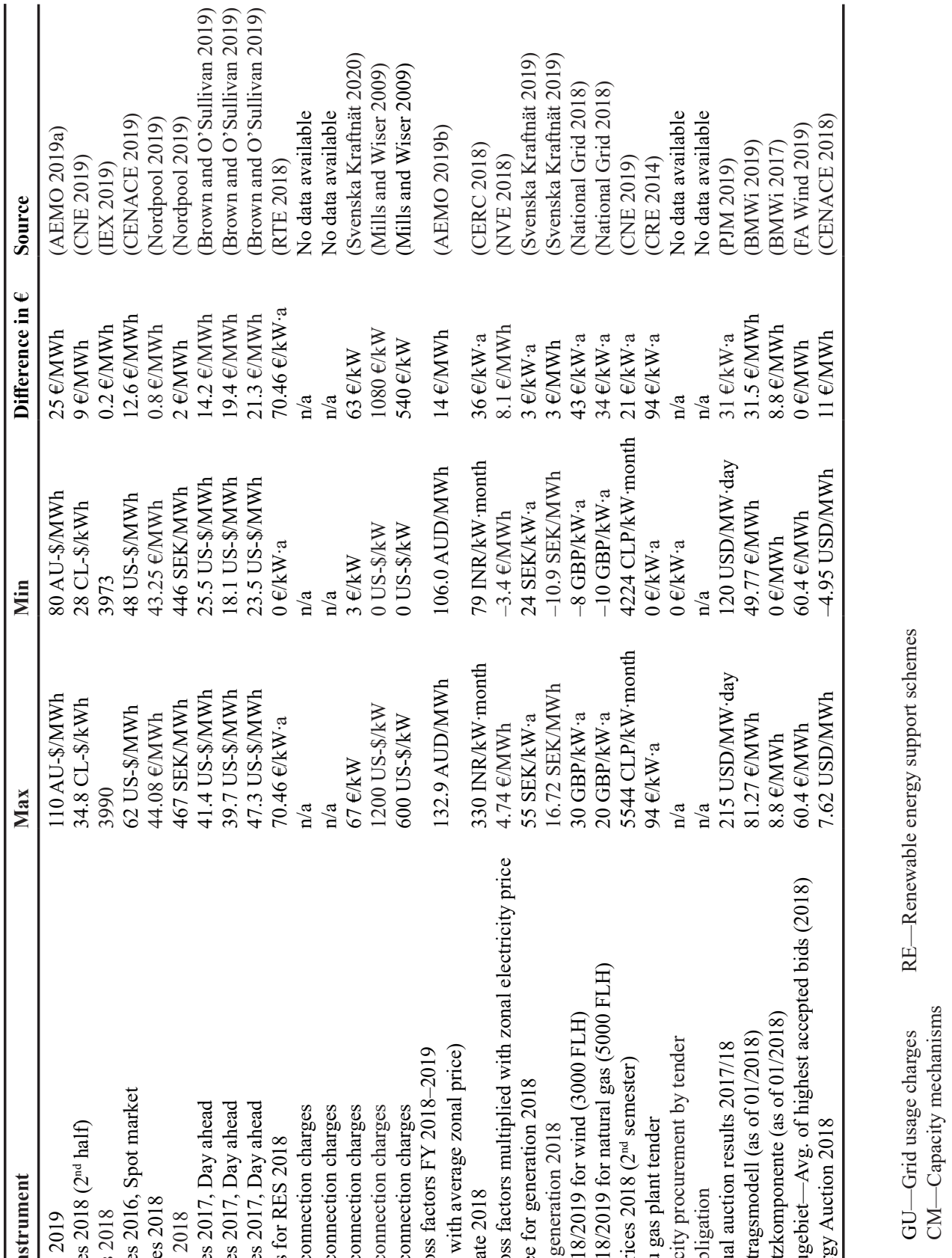


Table A.2: Magnitude of locational signals for combined cycle gas power plant (expressed in EUR per $k W$ )

\begin{tabular}{|c|c|c|c|c|c|c|c|c|c|c|c|c|}
\hline & 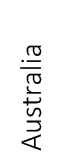 & $\frac{\varrho}{\frac{\omega}{U}}$ & 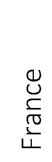 & 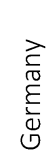 & $\stackrel{\frac{.0}{0}}{\underline{\underline{C}}}$ & $\begin{array}{l}\stackrel{O}{U} \\
\frac{X}{X} \\
\Sigma\end{array}$ & $\begin{array}{l}\sum_{0}^{\lambda} \\
\text { i } \\
z\end{array}$ & $\begin{array}{l}\frac{c}{d} \\
\frac{0}{0} \\
\sum_{n}\end{array}$ & 弚 & 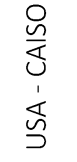 & 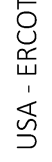 & 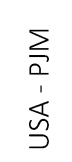 \\
\hline $\begin{array}{l}\text { Locational electricity } \\
\text { markets }\end{array}$ & 124 & 45 & & & 1 & 65 & 5 & 10 & & 70 & 97 & 105 \\
\hline Grid connection charges & & & & & & $*$ & $*$ & $5 *$ & & $75^{*}$ & & $40 *$ \\
\hline Grid usage charges & 72 & & & & 36 & & 41 & 20 & 34 & & & \\
\hline Capacity mechanisms & & 21 & 94 & $*$ & & & & & & $*$ & & 31 \\
\hline RE support schemes & & & & & & & & & & & & \\
\hline Combined effect & 137 & 60 & 94 & $*$ & 37 & $65^{*}$ & 46 & 24 & 35 & $145^{*}$ & 97 & $145^{*}$ \\
\hline *No or poor data availab & & & \multicolumn{4}{|c|}{$\begin{array}{l}\text { Locational instrument } \\
\text { (conv.) }\end{array}$} & & \multicolumn{5}{|c|}{$\begin{array}{l}\text { No locational instrument } \\
\text { (conv.) }\end{array}$} \\
\hline
\end{tabular}

Table A.3: Magnitude of locational signals for wind generation (expressed in EUR per $\mathrm{kW}$ )

\begin{tabular}{|c|c|c|c|c|c|c|c|c|c|c|c|c|}
\hline & 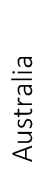 & 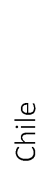 & 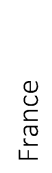 & 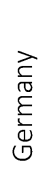 & $\stackrel{\frac{00}{0}}{\underline{\underline{O}}}$ & 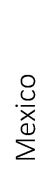 & $\begin{array}{l}\sum_{0}^{\overrightarrow{0}} \\
\text { i }\end{array}$ & $\begin{array}{l}\frac{c}{0} \\
\frac{0}{0} \\
\sum_{n}^{\prime}\end{array}$ & 弚 & 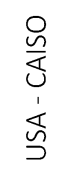 & 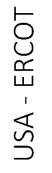 & 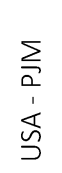 \\
\hline $\begin{array}{l}\text { Locational electricity } \\
\text { markets }\end{array}$ & 74 & 27 & & & 1 & 39 & 3 & 6 & & 42 & 58 & $63^{*}$ \\
\hline Grid connection charges & & & 70 & & & $*$ & $*$ & $6^{*}$ & & $78 *$ & & $39 *$ \\
\hline Grid usage charges & 43 & & & & & & 24 & 12 & 43 & & & \\
\hline Capacity mechanisms & & & & & & & & & & $*$ & & 31 \\
\hline RE support schemes & & & & 96 & & 33 & & & & & & \\
\hline Combined effect & 82 & 27 & 70 & 96 & 1 & 72 & $27^{*}$ & 24 & 42 & $120^{*}$ & 58 & 112 \\
\hline * No or poor data availabi & & & \multicolumn{4}{|c|}{$\begin{array}{l}\text { Locational instrument } \\
\text { (wind energy) }\end{array}$} & & \multicolumn{5}{|c|}{$\begin{array}{l}\text { No locational instrument } \\
\text { (wind energy) }\end{array}$} \\
\hline
\end{tabular}


AEMO (2019a). "Data Dashboard—Electricity Price Statistics for Australia.” https://aemo.com.au.

(2019b). "Marginal Loss Factors for the 2019-20 Financial Year." https://www.aemo.com.au.

BMWi (2017). "Verordnung Zu Den Gemeinsamen Ausschreibungen Für Windenergieanlagen an Land Und Solaranlagen." https://www.bmwi.de/.

- (2019). “Gesetz Für Den Ausbau Erneuerbarer Energien (Erneuerbare-Energien-Gesetz - EEG 2017).” http://www. gesetze-im-internet.de/eeg_2014/EEG_2017.pdf.

Brown, P.R., and F. O’Sullivan (2019). “Shaping Photovoltaic Array Output to Align with Changing Wholesale Electricity Price Profiles" Applied Energy. https://doi.org/10.1016/j.apenergy.2019.113734.

CENACE (2018). “Zonas de Precios—RE Auction.” https://www.cenace.gob.mx/.

(2019). "Historia de Precios de Energía Marginales Locales.” https://www.cenace.gob.mx.

CERC (2018). "Slab Rates for PoC Charges \& Losses 2018 - Order No. L-1/44/2010-CERC."

CNE (2019). "Precio Medio de Mercado 2018.” https://www.cne.cl/precio-medio-de-mercado-2/.

CRE (2014). "Landivisiau: Informations Complémentaires Sur Le Contexte Du Projet.” http://pref29.alkante.com/sit_1_

ALK/upload/actu/1301/document_reponse_AE.pdf.

FA Wind (2019). "8. Ausschreibung Für Windenergieanlagen an Land.” https://www.fachagentur-windenergie.de.

IEX (2019). "Area Prices | Indian Energy Exchange Ltd.” https://www.iexindia.com/marketdata/areaprice.aspx.

National Grid (2018). "Final Tariffs for 2018/19." https://www.nationalgrid.com.

Nordpool (2019). "Historical Market Data.” http://www.nordpoolspot.com/historical-market-data/.

NVE (2018). "The Norwegian Power System. Grid Connection and Licensing." http://publikasjoner.nve.no/.

PJM (2019). "Summary of 2018/2019 Base Residual Auction Results.” www.pjm.com.

RTE (2018). "Panorama de l'électricité Renouvelable En 2018.” https://www.rte-france.com.

Svenska Kraftnät (2019). "Tariff/Charges | Svenska Kraftnät.” https://www.svk.se/. (2020). "Interview with Santiago Piva on the 07. February 2020." 